\title{
SOR JUANA INÉS DE LA CRUZ HACE SUDAR LAS PRENSAS ESPAÑOLAS
}

\author{
Carla Anabella Fumagalli \\ (CONICET) \\ carlaafumagalli@gmail.com
}

RESUMEN: En este trabajo recorreremos las ediciones de la obra de sor Juana Inés de la Cruz con el objetivo de dar cuenta de algunos modos de legitimación de su autoría, de su obra y de sus publicaciones. Especialmente, atenderemos a los preliminares y paratextos que se señalan entre sí, no solo al interior de un libro, sino entre impresiones para indicar los recursos discursivos y editoriales que construyen la obra sorjuanina.

PAlABRAS Clave: Sor Juana Inés de la Cruz, Edición, Paratexto, Autoría, Legitimación.

\section{SOR JUANA INÉS DE LA CRUZ MAKES SPANISH PRESSES SWEAT}

ABSTRACT: In this article we will go over every edition of sister Juana Inés de la Cruz's literatura with the objective to highlight some of the ways in which her authorship, her work and her publications are legitimized. We will concentrate specially in the preliminaries and paratexts that point to each other, not only inside one book, but between printings to show the discursive and editorial resources that build sister Juana's work.

KEYwords: Sor Juana Inés de la Cruz, Edition, Paratext, Authorship, Legitimation.

\section{INUNDACIÓN CASTÁLIDA/POEMAS}

Varios pasajes en la obra de sor Juana Inés de la Cruz dan cuenta de los traslados - en barco, pero también de una manus scripturam a otra ${ }^{1}$ a los fue sometida. El primer libro que se imprime en la Península es Inundación castálida. ${ }^{2}$ Fue llevado por la condesa de Paredes cuando dejó finalmente México en 1688 (finalmente, porque su tiempo como virreina había concluido en 1686). Luego de una amistad que comenzara en 1680 y que quedó registrada en poemas de ambas manos, pero también en las recientemente encontradas cartas de la condesa a su prima, la duquesa de Aveiro y a su padre, Vespasiano Gonzaga; la condesa es el motor de la empresa editorial. En la primera de estas cartas, de 1682, ya le refiere a su prima su relación con sor Juana como el único placer que encuentra en su «grandísima soledad»: «Pues otra cosa de gusto que la visita de una monja que hay en san Jerónimo que es rara mujer no la hay» (Calvo y

\footnotetext{
${ }^{1}$ En el «Prólogo al lector» de 1690, al que me referiré más adelante, se lee: «que van de diversas letras, / y que algunas, de muchachos, / matan de suerte el sentido / que es cadáver el vocablo» (Juana Inés de la Cruz, 1690a: 1). Facundo Ruiz, en su edición de 2014, anota al respecto: «Con diversas letras se señala que las copias (manuscritas) de los poemas enviados a España para su publicación no serían de un mismo copista (por la prisa de los traslados, v.36 y epígrafe); de allí, que algunas de estas sean de muchachos, es decir (cf. Carta a Núñez: 379), de forma poco "razonable" (legible) o "decente" (al lector), dando lugar a que el sentido (alma) "muera" al confundirse el vocablo (cuerpo)» (Ruiz, 2014: 188).

${ }^{2}$ Título completo: Inundación castálida de la única poetisa, musa décima, soror Juana Inés de la Cruz: que en varios metros, idiomas, y estilos, fertiliza varios assumptos; con elegantes, sutiles, claros, ingeniosos, útiles versos: para enseñanza, recreo, y admiración.
} 
Colombi, 2015: 177). Este vínculo, explotado por la crítica desde diversos y criticables ángulos, ${ }^{3}$ es, independientemente de su naturaleza, fundamental, tanto en la escritura como en la difusión de la poesía de sor Juana, por lo menos la que se imprime en su primer volumen. Con el cambio de virreina, sor Juana busca nuevos mecenazgos, menos fructíferos quizás, aunque es justo decir que la vara que había dejado la condesa de Paredes era muy alta. Del siguiente vínculo de mecenazgo, con la condesa de Galve, encontramos testimonio en muchas poesías de ocasión, como en el famoso «Laberinto endecasílabo» del Segundo volumen (1692), pero no en las empresas editoriales de su obra propiamente dichas. El Segundo volumen está dedicado y es auspiciado por don Juan de Orúe y Arbieto, caballero de la orden de Santiago, mientras que el tercero es financiado por Juan Ignacio Castorena y Ursúa y dedicado a la reina Mariana de Neoburgo y a la marquesa del Valle de Oaxaca.

Volviendo a Inundación Castálida, este está compuesto casi enteramente por poesía, con excepción de la explicación en prosa del arco triunfal del Neptuno Alegórico, escrito con ocasión de la entrada de los virreyes, el conde de la Laguna y la condesa de Paredes, a México, en 1680. Las condiciones en que este libro se envía a España aparecen ya en el primer epígrafe del primer soneto, que muestra al lector no solo cómo es que apareció este libro en sus manos, sino ya, propiamente (tras algunos preliminares algo extensos —un romance de José Pérez de Montoro, un soneto de la religiosa Catalina de Alfaro, una aprobación del fraile Luis Tineo de Morales y un prólogo anónimo-), la poesía de la «única poetisa, musa décima». El epígrafe, harto conocido, dice: «A la excelentísima señora condesa de Paredes, marquesa de la Laguna, enviándole estos papeles que su excelencia la pidió y pudo recoger soror Juana de muchas manos, en que estaban no menos divididos que escondidos como tesoro, con otros que no cupo en el tiempo buscarlos ni copiarlos» (Juana Inés de la Cruz, 1689: 1). ${ }^{4}$ De todos modos, este rótulo (como todos los demás) no fue escrito por sor Juana, sino por alguien aún desconocido para la crítica, que se inclina entre dos hombres cercanos a la edición: Francisco de las Heras, secretario de la virreina (Alatorre, 1980: 466) o Juan Camacho Gayna, editor (Peñalosa, 1988: 130-136). ${ }^{5}$ De este modo, es a través de esta segunda mano que el lector, quien, gracias a los preliminares del libro, ya sabe algo sobre sor Juana (si es que no ha oído sobre ella antes de comprar su obra), se entera de cómo es que la poesía de una monja de clausura, mexicana, llegó a España. El epígrafe, además, repite lo indicado al respecto por el prologuista anónimo:

El soneto que sirve a este libro de dedicatoria le escribió a mi señora doña María Luisa de Gonzaga, condesa de Paredes, marquesa de la Laguna, su gran mecenas, cuando, habiéndose de volver a España, le envió a su excelencia, pedidos por curiosidad de buen gusto y mal unidos por desestima de la madre Juana Inés, unos cuadernos que amagaban a libro, y a estos escribió el soneto, desimaginada de que sus trabajos fuesen de tanto peso que aun hiciesen sudar en España las prensas (en Juana Inés de la Cruz, 1689: 8r).

Hay varios elementos comunes entre ambos textos, pero hay otros que se apuntan en el preliminar, que el epígrafe no recupera. De la circunstancia de la prisa se

${ }^{3}$ Me refiero a la hipótesis que sostiene la existencia de una relación romántica entre ambas, auspiciada principalmente por Octavio Paz (1982) y Antonio Alatorre (2001). Esta se vio reflejada en la película de María Luisa Bemberg, Yo, la peor de todas (Argentina, 1990) y, recientemente, en la serie de Patricia Arriaga Jordán, Juana Inés (Canal Once/Bravo Films, 2015). La última antología publicada en México por Sergio Téllez-Pon, Un amar ardiente (2017), se asienta en la misma hipótesis.

${ }^{4}$ He modernizado la ortografía y la puntuación de las citas a lo largo de todo este trabajo.

${ }^{5}$ Soriano Vallés da cuenta de la polémica en La hora más bella de sor Juana, 2008: 115. 
da cuenta únicamente en el epígrafe, mientras que en el prólogo se habla de las condiciones de producción que aún no se han dado, pero que funcionan como una predicción. Las prensas españolas sudarán con estos «cuadernos que amagaban a libro». De hecho, esta es la primera edición y no se tiene conocimiento de que se estuviera pensando en una segunda, aun cuando ocurriera menos de un año después. «Sudar la prensa» significa, según el Diccionario de Autoridades (1739), «imprimir mucho o continuamente». Esta locución concentra, entonces, un proyecto en ciernes, o ni siquiera un proyecto todavía, sino un deseo o especulación. Por otro lado, el prólogo concluye cuando se llama a sí mismo «prevención» y «advertencia» (Juana Inés de la Cruz, 1689: $8 \mathrm{v}$ ), y se orienta a aclarar el origen ocioso de sus poemas - vale decir, tiempo que sor Juana tiene libre de sus ocupaciones religiosas y que podría haber sido malgastado en vicios-, y cierra: «Bien sé que, mis advertencias no obstantes, como algo te parezca mal, dirás lo que te pareciere, que no mira el prólogo a otro fin que desarmarte la verdad en lo que acuses» (Juana Inés de la Cruz, 1689: 8v). El texto anónimo es una acalorada defensa de posibles ataques a la existencia misma de una monja escritora y, si bien hay pasajes de los preliminares en que se habla de su poesía como erudita, ingeniosa y clara, sus esfuerzos generales se concentran en desmentir lo que aún no ha sido pronunciado. Vale decir, intentan separar los juicios sobre la autora, de los versos allí recopilados y, si no es separarlos, sí es advertir sobre su vida antes de leer sus versos, como si esta información fuera fundamental a la hora de una buena interpretación poética.

Como decíamos, en 1690, una segunda edición de Inundación Castálida sale a las prensas con varias modificaciones. El título ya no es más el barroco arriba mencionado, sino el transparente Poemas de la única poetisa americana, musa décima... Además, hay cambios en varios epígrafes y se añaden algunos textos. Aunque no nos detendremos en este punto, conviene señalar que las modificaciones producidas afectan también al condicionamiento que el rótulo supone en la lectura e interpretación de cada poema. ${ }^{6}$ Para dar solo un brevísimo, pero no insólito ejemplo, las redondillas «Dos dudas en que escoger» sostienen una reflexión del yo poético femenino, marcado en sus inflexiones, acerca de cómo proceder en caso de no amar a quien lo ama. El epígrafe del poema en la edición de 1689 es: «Solicitada de amor importuno responde con entereza tan cortés que aun hace bienquisto el desaire» (Juana Inés de la Cruz, 1689: 14), de tal modo que admite, desde el participio pasivo femenino, la identificación del yo poético con la autora. En 1690, en cambio, el epígrafe dice: «Enseña modo con que la Hermosura, solicitada de Amor importuno, pueda quedarse fuera de él, con entereza tan cortés que haga bienquisto hasta el mismo desaire» (Juana Inés de la Cruz, 1690a: 14). En esta reelaboración, el yo poético enseña el modo en que la hermosura debe actuar si no ama a quien la ama. La separación de la hipotética situación del enredo amoroso es total y consecuente con las caracterizaciones que de la poeta se hace en los preliminares. Por ejemplo, en el soneto que sor Catalina Fernández de Córdoba dedica a sor Juana se lee: «Y si canta de amor, cuerda es tan fina / que no se oye rozada en lo indecente» (Juana Inés de la Cruz, 1689: 2v), sugiriendo la posibilidad de conectar indecencia con poesía de amor. La estrategia del editor es enderezar la posible interpretación de que sea la misma poeta quien «habla» en el poema y no una ficcionalización, como sugiere el epígrafe modificado, de la hermosura.

Entre los textos que se añaden en 1690, quizás el más relevante en lo que atañe a la producción editorial y el más conocido en el presente sea el «Prólogo al lector» (Juana Inés de la Cruz, 1690a: 7v-8v). En él, sor Juana se presenta a sus lectores en primera persona, les habla de su obra y de cómo debería ser leída. Con respecto a los

\footnotetext{
${ }^{6}$ Sobre las relaciones entre epígrafes y poemas en sor Juana véase Luciani, 1985.
} 
avatares de la publicación, a la «prisa de los traslados» se le suma la falta de disposición de sor Juana para la prensa, como se lee en los famosos versos «No agradecido te busco: / pues no debes, bien mirado, / estimar lo que yo nunca / juzgué que fuera a tus manos» (Juana Inés de la Cruz, 1690a: 7v). Además, se añaden las circunstancias de la producción misma de los textos, que se hacen eco del prólogo anónimo de la primera edición (que ya no se publicará) y de la aprobación del fraile Luis Tineo de Morales (presente en todas las ediciones de este primer volumen). En el «Prólogo al lector», sor Juana afirma que su escritura es producto del tiempo robado al ocio: «cuando los he hecho, / ha sido en el corto espacio / que ferian al ocio / las precisiones de mi estado» (Juana Inés de la Cruz, año: 8r). Así, ahora en boca de la monja, se repite el fragmento que citamos del prólogo anónimo, que ahora se omite. La legitimación de la misma existencia de la obra, que el lector tiene en sus manos, está dada por las condiciones de su producción: no fue tarea profesional -propia de la vida monástica, llena de ocupaciones-, ${ }^{7}$ sino ociosa.

De este modo, en solo ocho meses se ha puesto al lector en conocimiento de las circunstancias básicas de producción, edición e impresión del primer tomo de las poesías de una monja mexicana, tanto por parte de representantes de la Iglesia (Tineo de Morales), ${ }^{8}$ como de poetas de prestigio (Pérez de Montoro), ${ }^{9}$ como de la autora. Estas poesías fueron escritas en los momentos que dispensaba la tarea conventual, recogidas con prisa, desprolijamente, de varias manos, probablemente de modo incompleto en un cuaderno, que no era todavía un libro, y trasladadas desde México a España por una mujer, la condesa de Paredes, a quien además se le dedica el libro (y muchos de los textos que contiene). Esta condesa delega las tareas, probablemente, de edición e impresión en un caballero ya conocido, Juan Camacho Gayna/Jayna, cuyo nombre aparecerá en las portadas de todas las ediciones del primer volumen (con excepción de la de Zaragoza de 1692) desde 1689 hasta 1725; no así el de la condesa, que desaparece tras la madrileña de 1690. Esta reedición también tiene el valor agregado de informar en su portada de que es una «Segunda edición, corregida y mejorada por su autora». Las correcciones y mejoras son terreno de debate para la crítica, del mismo modo que sucede con las ediciones de 1691 en Barcelona, en cuya portada se anuncia que se trata de una «Tercera edición, corregida y añadida por su autora». ${ }^{10}$ Hasta 1691 cada edición es distinta; luego se reproduce, con excepción de las de Valencia de 1709 y la de Madrid de 1714, siempre la de 1691.

Este primer volumen se reeditará una vez por año hasta 1692, luego dos veces en 1709, una vez más en 1714 y dos en 1725 . Un total de nueve reediciones tiene el primer tomo de poesías de sor Juana Inés de la Cruz. Pero esto no es lo más sorprendente o específico de su historia editorial, sino que la impresión de sus otros tomos coincida con

\footnotetext{
${ }^{7}$ Para saber más sobre las ocupaciones de las monjas novohispanas del siglo XVII, véase Lavrin, 2016.

${ }^{8}$ En la «Aprobación del reverendísimo P. M. Fr. Luis Tineo de Morales, del orden de canónigos r[e]glares premonstratenses, maestro general de su religión, predicador de Su Majestad, y su teólogo de la Real Junta de la Purísima Concepción, abad del convento de san Joaquín de esta corte» (Juana Inés de la Cruz, 1689, 1690a: 3r-6r).

${ }^{9}$ Con el romance dedicado a sor Juana, que se incluye en ambas ediciones (Juana Inés de la Cruz, 1689, 1690a: f. 2).

${ }^{10}$ Los problemas que encuentra la crítica para considerar que fue sor Juana quien corrigió y añadió personalmente textos entre 1689 y 1690 se deben a que entre una y otra edición transcurren ocho meses, tiempo insuficiente para que los papeles viajen ida y vuelta entre México y Madrid, aunque Sabat de Rivers (1999: 26) finalmente considera que pudo haber sido posible por las vueltas de correo. Algunos añadidos, con excepción de los sonetos satíricos, son estimados por Alatorre y Tenorio como «traspapelados» (Tenorio, 2011: 560). Sobre la participación de sor Juana en la edición de 1691, la crítica no ha desconfiado, hasta donde tengo entendido.
} 
las reimpresiones de los anteriores, evidenciando, si no una demanda de los lectores por todos los libros de la poetisa, sí una apuesta económica frecuente de varios editores. ${ }^{11}$

\section{SEGUNDO VOLUMEN}

En 1692 se publica, en Sevilla, el Segundo volumen de las obras de soror Juana Inés de la Cruz... A partir de este título, sus libros gozarán de cierta interreferencialidad. Ninguno de ellos será completamente autónomo, como sucedía con el primero. Quizás esto sea una consecuencia de que el género es compartido, ya que los versos amalgaman los tomos. Sin embargo, si vemos volúmenes como el segundo y, el caso más extremo a este respecto, el último, Fama y obras póstumas (al que nos referiremos en extenso más adelante), los contenidos literarios de cada uno difieren bastante del primero, que adopta el nombre de Poemas. En el Segundo volumen se edita la «Crisis de un sermón», ${ }^{12}$ título compuesto para este libro, ya que en pliego suelto era la Carta atenagórica (1690b), como había propuesto su editor, el obispo Manuel Fernández de Santa Cruz. Además, contiene poesía religiosa ${ }^{13}$ —entre la que se cuentan varios autos con sus loas-, «poesías líricas» profanas —el Primero sueño (1692: 247-276) y otros poemas (277350) — y «poesías cómicas» (351-532) — donde destacan las comedias Los empeños de una casa y Amor es más laberinto-. En Fama y obras póstumas (Juana Inés de la Cruz, 1700) se publican principalmente poemas laudatorios, la aprobación que luego se llamará Vida del padre Diego Calleja (8r-18v) y, de sor Juana, la Respuesta a sor Filotea (8-60), unos ejercicios devotos, sus protestas de fe y nueve poemas. Así, la especie no condiciona el modo en que se refieren sus continentes entre sí. Entonces, ¿por qué estos volúmenes se presentan a sí mismos como interdependientes? Una explicación quizás evidente es el hecho de que, al mencionar las demás obras de la autora en portadas o preliminares, los impresores y mercaderes tenían más posibilidades de vender los demás volúmenes. Pero ¿cuántos de los libros de sor Juana fueron editados o impresos por las mismas personas? De hecho, son muy pocos los impresores y mercaderes que imprimieron una sola vez a la monja mexicana. Son los casos de Manuel Román y Matías de Lezaun, que imprimen en 1692 Poemas... en Zaragoza, así como los impresores del mismo libro, en dos oportunidades, en Valencia, en 1709, Antonio Bordázar y José Cardona. O los casos de quienes entre 1700 y 1701 imprimieron Fama y obras póstumas, Manuel Ruiz de Murga en Madrid, Miguel Deslandes en Lisboa, y Rafael Figueró en Barcelona. De este modo, de veinte libros impresos, solo seis lo fueron por quienes se dedicarían solo en una ocasión a la obra de sor Juana Inés. Todos los demás decidieron invertir más de una vez en la poeta mexicana. Los títulos y los preliminares, entonces, ayudaban también al negocio de quienes los ponían en prensa, aunque, llamativamente, quienes ocuparon sus talleres con las primeras ediciones no continuaron haciendo lo mismo con los libros que siguieron. De todos modos, la fama, ya real y previa a la publicación (aunque limitada a Nueva España) - como se puede aventurar a partir de las menciones que de la monja hace la condesa de Paredes, su mecenas, en la citada carta de 1682 a su prima, la duquesa de Aveiro-, ya construida - como en el prólogo anónimo en Inundación

${ }^{11}$ Jaime Moll llama a la reedición de una primera edición exitosa de otro editor una «reedición de éxito vivo» (2011: 93).

12 «Crisis sobre un sermón de un orador grande entre los mayores, que la madre soror Juana llamó Respuesta, por las gallardas soluciones con que responde a la facundia de sus discursos» (Juana Inés de la Cruz, 1692a: 1-34).

13 Dividida entre poesías «lírico-sacras» (Juana Inés de la Cruz, 1692a: 35-104) y «cómicosacras» (105-246), y, al final del volumen «Más poesías lírico-sacras» (533-546). 
Castálida -; ya considerada como bien de cambio y entendida como el producto de la profusa circulación de sus textos y el consecuente conocimiento popular de su figura y/o viceversa, genera un valor añadido a cualquiera de los tomos sorjuaninos, sean vendidos por separado o en conjunto, por el mismo o por más de un mercader.

En los preliminares del Segundo volumen, quienes escriben aprobaciones, licencias y poemas laudatorios remiten constantemente al primero. Por ejemplo, cuando el padre Juan Navarro Vélez se refiere en su aprobación a las circunstancias de publicación, nuevamente se repiten las de Inundación Castálida: «Y si estos papeles esparcidos y divididos parecieron tan buenos aun a los más doctos, recogidos y juntos en un volumen es preciso que parezcan buenos en superlativo grado, y que se granjeen los más crecidos elogios». Además: «Comenzó a manifestar las luces de su vivísimo ingenio la madre Juana en el primer tomo de sus obras»; o «el mayor elogio y el más elegante panegírico con que pueden coronarse los primores de este segundo tomo son la aclamación y los aplausos con que fueron recibidos los aciertos del primero». En la censura de Cristóbal Báñez de Salcedo leemos: «Cuyo motivo [el de la impresión] me obliga a sentir debérsele no solo la permisión, sino también el precepto para que se dé a la luz pública este volumen, que continúe con el primero la estimación de este sublime honor de nuestro tiempo» (en Juana Inés de la Cruz, 1692a: 3v-6v). También ocurre en la «Nota» que presenta los textos panegíricos:

Habiendo don Juan de Orúe y Arbieto de dar a la luz pública este Segundo volumen de las obras de la madre Juana Inés de la Cruz, o por anticiparles el gusto de leerlas, o por examinar si corrían uniformes en aquel aplauso universal con que fue recibido el primer tomo, las consultó con algunos varones insignes en religión y letras, remitiéndoselas para que las viesen; y hallando por las respuestas dadas a su consulta eruditamente confirmada la fama de su autora, no ha querido defraudarla de tan relevantes expresiones, ni a la curiosidad de los lectores de la vista y tan brillantes elogios; y así los ofrece consecutivos, ocupando las veces del más proporcionado y elegante preludio (Juana Inés de la Cruz, 1692a: 8v).

Esta nota no solo se refiere al primer tomo, sino que depende de él para verificar que la fama de sor Juana sigue intacta, y que este nuevo libro tendrá el mismo éxito. Esta puesta en escena del pedido de los panegíricos, ya sea para dar a leer los textos a amigos antes de que salieran a la prensa - como mencionan algunos textos-, ya para confirmar que la fama del primer volumen y de sor Juana hasta ese momento serían suficientes para soportar el peso de esta segunda empresa, es muy interesante a la hora de considerar los modos de legitimación de autor y obra en los preliminares de un libro, no solo evidencia la fama pública previa de la autora, sino que se proyecta hacia el futuro, a partir de la introducción de un aparato panegírico que ofrecerá una lectura guiada a los textos más importantes del volumen: la «Crisis» y el «Primero sueño». ${ }^{14}$ Los autores de estas prosas y poesías señalan en repetidas oportunidades estos dos textos por su título o con alusiones evidentes a ellos, para encumbrarlos en el tomo, que, recordemos, comienza con la «Crisis», mientras el «Primero sueño» encabeza la sección titulada «Poesías líricas». Estos preliminares, entonces, singularizan los dos textos que más polémicas suscitaron en aquel siglo y los siguientes como los de mayor valor y potencial legitimidad autoral para sor Juana. La «Crisis», el texto que la monja, en

${ }^{14}$ Es interesante dar cuenta del beneficio que ser incluido en una obra como la de la famosa poeta mexicana traía para estos escritores. Como señala Alain Bègue (2009: 103): «si bien adoptan la retórica y el estilo propios del discurso laudatorio, lo enmarcan en un molde similar al de la aprobación, con el propósito implícito de aprovechar el renombre de la escritora novohispana, ya establecido en la Península, pero en beneficio de los autores de estas prosas circunstanciales». 
repetidas oportunidades, dice no haber escrito ni publicado por voluntad propia, el único texto que tuvo verdaderos detractores, el texto que abiertamente polemiza sobre teología. ${ }^{15} \mathrm{Y}$ «Primero sueño», el único poema que sor Juana advierte haber escrito por voluntad propia, ${ }^{16}$ el más largo y complejo de ellos, del que el padre Navarro Vélez dice, en su censura, que «ha menester ingenio bien despierto quien hubiere de descifrarle, y me parece no desproporcionado argumento de pluma docta el que con la luz de unos comentarios se vea ilustrado, para que todos gocen los preciosísimos tesoros de que está rico» (1692: 4v). Este religioso, guiado quizás por el epígrafe del poema que lo conecta con don Luis de Góngora, está pensando en las Soledades comentadas de García de Salcedo Coronel, de 1636, una publicación contextualizada en la polémica en torno a Góngora que se dedicaba a defender la dificultad de las Soledades explicando el poema con comentarios a breves fragmentos, como ya lo había hecho con el Polifemo en 1629. El censor lee el poema mientras piensa en una posible (y útil) futura publicación (que no llegará, pero cuya proyección desde los preliminares densifica la relación con los textos del libro).

Este Segundo volumen se volverá a imprimir en tres ocasiones en 1693 en Barcelona, ${ }^{17}$ una vez más en $1715 \mathrm{y}$, por último, en 1725.

\section{FAMA Y OBRAS PÓSTUMAS}

Finalmente, cinco años después de la muerte de su autora, llega a las prensas la Fama y obras póstumas de sor Juana Inés de la Cruz, editado por Juan Ignacio de Castorena y Ursúa. ${ }^{18}$ Este curioso volumen -que se reimprime en 1710 en Madrid y Barcelona, en 1714 y dos veces en Madrid en 1725- alberga un porcentaje muy menor de las obras para concentrarse principalmente en la fama. Sin embargo, a este libro le debemos la impresión de la Respuesta a sor Filotea, acompañada por primera vez de la Carta de sor Filotea ${ }^{19}$ y del poema inconcluso «Cuándo, númenes divinos» (Juana Inés

${ }^{15}$ En la Respuesta a sor Filotea: «El segundo imposible es saber agradeceros tan excesivo, como no esperado favor, de dar a las prensas mis borrones»; y luego, «porque quien hizo imprimir la Carta tan sin noticia mía, quien la intituló, quien la costeó, quien la honró tanto, siendo de todo indigna por sí y por su autora, ¿qué no hará?» (Juana Inés de la Cruz, 1700: 8, 12); en el comienzo de la misma «Crisis»: «De las bachillerías de una conversación, que en la merced que me hace pasaron plaza de vivezas, nació en v. md. el deseo de ver por escrito algunos discursos que allí hice de repente» (Juana Inés de la Cruz, 1692: 1), y también lo refiere Fernández de Santa Cruz en su Carta de Puebla: «Empezando por el último capítulo, en que V. md. me manifiesta la contradicción que ha padecido la Carta atenagórica, tan sin culpa de V. md. que no hubo parte en su impresión, debo poner en la noticia de V. md. que uno de los principales motivos que hubo el que la sacó a luz fue desear manifestar a la Europa, a donde han ido algunas copias, que la América no solo es rica de minas de plata y oro, sino mucho más de aventajados ingenios (bien ajeno que pudiese haber juicio que disputase a V. md. la sutileza, viveza y solidez de sus discursos)» (en Soriano Vallés, 2015: 191).

${ }^{16}$ En la Respuesta a sor Filotea: «Demás que yo nunca he escrito cosa alguna por mi voluntad, sino por ruegos y preceptos ajenos; de tal manera que no me acuerdo haber escrito por mi gusto si no es un papelillo, que llaman el Sueño» (Juana Inés de la Cruz, 1700: 14).

${ }^{17}$ Véase Sabat de Rivers, 1995.

18 Para una descripción pormenorizada de la disposición de los preliminares de Fama y obras póstumas véase Alatorre, 1980, y Fumagalli, 2016.

${ }^{19}$ La Carta de sor Filotea acompañaba la impresión de la Carta atenagórica en la edición de Puebla del obispo Manuel Fernández de Santa Cruz en 1690 (Juana Inés de la Cruz, 1690b). Si bien se conoce una edición de 1692 hecha en Palma de Mallorca por Miguel Capó, citada por Abreu Gómez (1934: 248) y Salceda (1957: 404, n.), se ignora la difusión que pudo haber tenido este impreso. Castorena habla — en el «Prólogo»— de la Carta de sor Filotea como inédita: «admirarás para la madre Juana una carta que la alienta y una aprobación que la resucita» (en Juana Inés de la Cruz, 1700: 30r). La aprobación a la que se refiere es el texto biográfico escrito por Diego Calleja. 
de la Cruz, 1700: 157-162), entre otros textos. ${ }^{20}$ El proyecto editorial de Castorena era muy importante. Fue el encargado de trasladar los escritos de la monja mexicana a la península, además de solicitar panegíricos y elegías a sesenta y una personas, españoles y mexicanos en distintas proporciones. ${ }^{21}$ Acerca de las condiciones de esta publicación, en su prólogo, Castorena señala sus deseos para la edición, algunos alcanzados y muchos otros no:

Esperaba también recoger otros manuscritos de la poetisa, y este, con sus originales, colocarlos en el estante que dorando ocupan sus dos antecedentes en el Escorial, donde, como de ingeniosa prole del máximo doctor y padre san Jerónimo, los deposita la gran librería de religiosos jerónimos en su convento de San Lorenzo el Real [...] quedáronseme en la América, pues cuando me transporté de Nueva España a estos reinos no los pude haber a las manos, pero sí con certidumbre a la memoria. Retíromelos lo huraño, con noble ambición de atesorarlos, o rescatólos la discreción de mesurada prudencia, que malogré obligar con mis instancias por la precisión de mi viaje (en Juana Inés de la Cruz, 1700: 64v).

Castorena da cuenta asimismo de los textos que quedaron fuera del volumen, ${ }^{22} \mathrm{y}$ alude además a otros «muchos papeles y cartas» que, «sin duda», debió de escribir sor Juana, pero «como jamás desvaneció su humildad la esperanza de darlos a las prensas, los despedía hasta en los borradores, y sin dificultad, se perdieron» (en Juana Inés de la Cruz, 1700: 67r). Este traslado de textos póstumos no supuso entonces el traslado de todos ellos, sino de aquellos que no se perdieron después de escritos ni fueron retenidos por otras manos en México. Otra vez, el traslado, los textos repartidos, las copias destruidas signan las condiciones de producción del último libro de sor Juana, y establecen una imagen de obra abierta, susceptible a los cambios y los «papeles encontrados», como se la sigue pensando desde la crítica hasta hoy. ${ }^{23}$

Como el Segundo volumen, este también se refiere constantemente a los anteriores, aunque ya no para apoyarse en ellos, sino porque la tradición de las Famas requiere no solo la descripción de la vida del homenajeado, a manos de Diego Calleja en el caso de sor Juana, sino ineludibles menciones a su obra, proveyendo un contexto de publicación y una justificación de impresión. La mayoría de los poemas paratextuales de Fama y obras póstumas menciona este libro como el «tercer tomo de sus poesías». Incluso, en muchos de ellos se retoma la metáfora biológica que ya había sido esbozada en el Segundo volumen, y así, por ejemplo, Juan de Bolea Alvarado escribe unos madrigales enteros sobre esta (en Juana Inés de la Cruz, 1700: 34r-35r). ${ }^{24}$ Dice: «Ella [la ciencia] fue la que dio primer efecto / del verdor de tu ingenio soberano, / también asegundando aquel perfecto / tejido ramillete de tu mano; / mas en este tercero

${ }^{20}$ Castorena señala el poema como inconcluso, aunque Beatriz Colombi (2017) propone una interesante lectura alternativa.

${ }^{21}$ Cuento tanto los participantes que firmaron con su nombre en el volumen, como los textos anónimos cuya autoría Antonio Alatorre sugiere que es de Castorena (1980: 440, 497, 507).

22 «Una glosa en décimas [...]; las Súmulas que de su letra tenía el reverendo padre maestro José de Porras [...]; el Equilibrio moral, direcciones prácticas morales en la segura probabilidad de las acciones humanas [...]; un poema que dejó sin acabar don Agustín de Salazar y perficionó con graciosa propiedad la poetisa» (en Juana Inés de la Cruz, 1700: 67r). Este último poema es la comedia la Segunda Celestina. Sobre los avatares de este texto, véase Sabat de Rivers, 1992.

${ }^{23}$ Para un resumen de los «papeles encontrados» véase Fumagalli, 2018.

${ }^{24}$ Precede al poema este epígrafe: «Al tercer tomo de la única poetisa sor Juana Inés de la Cruz, que publica el doctor D. Juan Ignacio de Castorena [...] Pondérase que siendo el primer tomo doctísimos verdores de poética erudición; el segundo, fragantísimo ramillete de matizadas flores, este tercer tomo es de sazonados frutos y utilísimos desengaños. Madrigales» (34r). 
nos da el fruto / de tu discurso y gran entendimiento» (35r). En estos preliminares no se hace referencia a la muerte de la poetisa, a su vida y a sus otros dos tomos como un modo de contextualizar la publicación de este, llamado constantemente «tercer tomo». El asunto de los títulos en los libros publicados en el siglo XVII es interesante. Si nos concentramos en los de sor Juana, podemos ver que cambian entre preliminares y portadas. Por ejemplo, Fama póstuma, como mencionábamos, se nombra en los poemas como «tercer tomo»; las aprobaciones lo llaman Obras y fama póstuma, mientras que la fe de erratas, la suma del privilegio y la suma de la tasa lo llaman Fama y obras póstumas. Las dos impresiones siguientes, de 1701 en Lisboa y Barcelona titulan en portada: Fama y obras pósthumas. Tomo tercero del fénix de México. Por otro lado, el hecho de que las obras impresas sean póstumas garantiza el cierre de la colección (aunque no de la obra, como mencioné antes). La inestabilidad titular también se aprecia en los tomos anteriores, muy especialmente en el primero. Mientras la portada titula Inundación castálida, el «Privilegio» del libro lo hace como Varios poemas castellanos de soror Juana Inés de la Cruz, y la «Fe de erratas», Poemas de soror Juana Inés de la Cruz, religiosa profesa en el convento de S. Jerónimo de la ciudad de México. De este modo, se puede apreciar cierta fluctuación entre títulos aun dentro del mismo libro que nombran. Sin embargo, a partir de la publicación del Segundo volumen, al que se llama en preliminares, tasas y fe de erratas alternativamente Segundo volumen, Segundo tomo o Segunda parte, se comienza a hacer de Inundación castálida parte de algo mayor.

\section{EL CONJUNTO}

Para concluir, propongo ver - a modo de panorámica editorial - en conjunto y ordenadas cronológicamente, todas las obras de sor Juana Inés. Usaré los números I, II y III para consignar respectivamente las ediciones de Inundación castálida o Poemas (como se llama desde 1690), el Segundo volumen y Fama y obras póstumas. No añadiré en esta lista más detalle de cada impresión, excepto el año y el lugar, porque quiero que el lector aprecie no la profusión de ediciones, que ya mencioné a lo largo del texto, sino su distribución.

\begin{tabular}{|ll|ll|}
\hline 1689 & I Madrid & 1709 & I Valencia \\
$1690 \mathrm{a}$ & I Madrid & 1709 & I Valencia \\
1691 & I Barcelona & $1714 \mathrm{a}$ & I Madrid \\
$1692 \mathrm{~b}$ & I Zaragoza & $1714 \mathrm{~b}$ & III Madrid \\
$1692 \mathrm{a}$ & II Sevilla & 1715 & II Madrid \\
1693 & II Barcelona & $1725 \mathrm{a}$ & I Madrid \\
1693 & II Barcelona & $1725 \mathrm{~b}$ & I Madrid \\
1693 & II Barcelona & $1725 \mathrm{c}$ & II Madrid \\
1700 & III Madrid & $1725 \mathrm{~d}$ & III Madrid \\
$1701 \mathrm{a}$ & III Lisboa & & \\
$1701 \mathrm{~b}$ & III Barcelona & & \\
\hline
\end{tabular}

Dividí el cuadro en dos columnas y las ediciones a partir de las de 1709 por un motivo. Si vemos el lado izquierdo, las publicaciones son sucesivas, cronológicas. Más allá de la coincidencia en 1692 de que se imprimen tanto el I como el II, en 1709 se reedita el I y luego, desde 1714, se editan dos veces sus tres tomos juntos. Esta distribución hace pensar que el «éxito vivo» que señala Moll (2011: 93) es muy evidente en las obras de sor Juana. Una vez que un editor asumía el riesgo y publicaba 
por primera vez cada libro, otros aprovechaban y compartían el éxito. Además, todas las primeras ediciones se publican con privilegio, ${ }^{25} \mathrm{y}$ todas tienen reediciones inmediatas fuera del reino en que este había sido otorgado. La de 1690 es del mismo editor, Juan Camacho Gayna, mientras que en 1691 se reedita en Barcelona (aunque esta es una edición con añadidos) y en 1692 en Zaragoza, fuera de Castilla. Del Segundo volumen hay reediciones inmediatas en Barcelona, y del tercero, en Lisboa y también Barcelona. De este modo vemos, como señala Moll (2011: 94-95), que:

si la obra logra un gran éxito, sus naturales beneficios los ha de compartir [el editor a cargo de la primera edición] — sin desearlo - con otros editores, los que hayan lanzado ediciones legales en otros reinos donde la obra no estaba privilegiada, o con los editores de ediciones contrahechas y falsificadas impresas en el propio reino donde un privilegio protege la obra [...] al aumento de lectores por la aceptación de una obra puede añadirse la multiplicación de aquellos, al acceder dicha obra a mercados antes cerrados a la misma.

La multiplicación de lectores y de mercados también requería una legitimación sistematizada entre los volúmenes. Como vimos a lo largo de este recorrido por las ediciones de la obra de sor Juana Inés de la Cruz, es en los preliminares, pero también en las portadas y en los epígrafes, donde se construye una legitimación autoral y de la obra sorjuanina que se basa en las condiciones de producción, de recopilación, de edición y de impresión, algunas propias de la época y otras propias de la circulación de la obra de una autora que, desde el principio, supuso un ejercicio de escritura también para quienes quisieron publicarla.

\section{OBRAS CITADAS}

Fuentes primarias: ediciones de sor Juana Inés de la Cruz

Juana Inés de la Cruz, sor (1689), Inundación castálida de la única poetisa musa décima..., Madrid, Juan García Infanzón.

Juana Inés de la Cruz, sor (1690a), Poemas de la única poetisa americana musa décima..., Madrid, Juan García Infanzón.

Juana Inés de la Cruz, sor (1690b), Carta atenagórica de la Madre Juana Inés de la Cruz, religiosa profesa de velo y coro en el muy religioso convento de San Jerónimo de la ciudad de Méjico, cabeza de la Nueva España, Puebla de los Ángeles, Diego Fernández de León.

Juana Inés de la Cruz, sor (1691), Poemas de la única poetisa americana, musa décima..., Barcelona, Joseph Llopis.

Juana Inés de la Cruz, sor (1692a), Segundo volumen de las obras de soror Juana Inés de la Cruz..., Sevilla, Tomás López de Haro.

Juana Inés de la Cruz, sor (1692b), Poemas de la única poetisa americana, musa décima..., Zaragoza, Matias de Lezaun.

Juana Inés de la Cruz, sor (1693), Segundo volumen de las obras de soror Juana Inés de la Cruz..., Barcelona, José Llopis. [Tres ediciones]

${ }^{25}$ El privilegio era un documento legal que otorgaba la exclusividad de una impresión a determinada persona, generalmente por diez años en determinado territorio. Si ese privilegio era violado, es decir, si otra persona realizaba una impresión en el mismo lugar mientras durara la exclusividad, podía sufrir multas entre diez mil y cien mil maravedís, o la pérdida de libros y aparatos (Reyes Gómez, 2001: 189). 
Juana Inés de la Cruz, sor (1700), Fama y obras póstumas del Fénix de México..., Madrid, Manuel Ruiz de Murga.

Juana Inés de la Cruz, sor (1701a), Fama y obras póstumas del Fénix de México..., Lisboa, Miguel Deslandes.

Juana Inés de la Cruz, sor (1701b), Fama y obras póstumas del Fénix de México..., Barcelona, Rafael Figueró.

Juana Inés de la Cruz, sor (1709), Poemas de la única poetisa americana musa décima..., Valencia, Antonio Bordazar. [Dos ediciones]

Juana Inés de la Cruz, sor (1714a), Poemas de la única poetisa americana musa décima..., Madrid, José Rodríguez y Escobar.

Juana Inés de la Cruz, sor (1714b), Fama y obras póstumas, tomo tercero del Fénix de México y décima musa, poetisa americana..., Madrid, A. González de Reyes.

Juana Inés de la Cruz, sor (1715), Obras poéticas de la musa mexicana soror Juana Inés de la Cruz... Tomo segundo añadido por su autora..., Madrid, José Rodríguez de Escobar.

Juana Inés de la Cruz, sor (1725a), Tomo primero. Poemas de la única poetisa americana, musa décima, soror Juana Inés de la Cruz..., Madrid, Ángel Pasqual Rubio.

Juana Inés de la Cruz, sor (1725b), Tomo primero. Poemas de la única poetisa americana, musa décima, soror Juana Inés de la Cruz..., Madrid, Francisco López.

Juana Inés de la Cruz, sor (1725c), Segundo Tomo de las Obras de soror Juana Inés de la Cruz..., Madrid, Ángel Pascual Rubio.

Juana Inés de la Cruz, sor (1725d), Fama y Obras Pósthumas, Tomo Tercero, del Fénix de México, y Dezima Musa, Poetisa Americana..., Madrid, Ángel Pascual Rubio.

\section{Bibliografía secundaria}

Abreu Gómez, Ermilo (1934), Sor Juana Inés de la Cruz: bibliografía y biblioteca, México, Imprenta de la Secretaría de Relaciones Exteriores.

Alatorre, Antonio (1980), «Para leer la Fama y obras póstumas de Sor Juana Inés de la Cruz», Nueva Revista de Filología Hispánica, XXIX, 2, pp. 428-508.

Alatorre, Antonio (2001), «María Luisa y sor Juana», Periódico de Poesía, 2, pp. 8-37.

Bègue, Alain (2011), «De leyes y poetas. La poesía de entre siglos a la luz de las aprobaciones (siglos XVII-XVIII)», en María Soledad Arredondo, Pierre Civil y Michel Moner (eds.), Paratextos en la literatura española (siglo XVII-XVIII), Madrid, Casa de Velázquez, pp. 91-107.

Calvo, Hortensia y Beatriz Colombi (2015), Cartas de Lysi. La mecenas de sor Juana Inés de la Cruz en correspondencia inédita, Madrid/Frankfurt/México, Iberoamericana/Vervuert.

Chartier, Roger (2006), «Materialidad del texto, textualidad del libro», Orbis Tertius, 11-12, <www.orbistertius.unlp.edu.ar/article/download/ OTv11n12a01/3774>.

Colombi, Beatriz (2017), «Sor Juana Inés de la Cruz ante la fama», Prolija memoria. Segunda época, I, 1, pp. 9-30.

Díaz, José Simón (2000) [1983], El libro español antiguo. Análisis de su estructura, Madrid, Ollero y Ramos.

Diccionario de Autoridades (1739), tomo VI.

Eguía-Lis Ponce, Gabriela (2002), La prisa de los traslados: análisis crítico e interpretación de variantes encontradas en las ediciones antiguas (siglo XVII y XVIII) de los tres tomos de la obra de Sor Juana Inés de la Cruz, Tesis doctoral, UNAM.

Fumagalli, Carla (2016), «La fama en Fama y Obras Pósthumas», en Beatriz Colombi (coord.), Viajes, desplazamientos e interacciones culturales en la literatura latinoamericana de la conquista a la modernidad, Buenos Aires, Biblos, pp. 67-82.

Fumagalli, Carla (2018), «Sor Juana Inés de la Cruz: articulaciones entre obra y archivo en los preliminares de sus ediciones originales», Anclajes, XXII, 1, pp. 37-53.

Juana Inés de la Cruz, sor (1957), Obras completas. Tomo IV, prólogo y notas Alberto G. Salceda, México, Fondo de Cultura Económica.

Juana Inés de la Cruz, sor (2017), Un amar ardiente, comp. Sergio Téllez Pon, Madrid, Flores raras. 
Lavrin, Asunción (2016), Las esposas de Cristo. La vida conventual en Nueva España, México, Fondo de Cultura Económica.

Luciani, Frederick (1985), «Sor Juana Inés de la Cruz: Epígrafe, epíteto, epígono», Letras Femeninas, XI, 1-2, pp. 84-90.

Moll, Jaime (2011), Problemas bibliográficos del Siglo de Oro, Madrid, Arco Libros.

Paz, Octavio (1982), Sor Juana Inés de la Cruz o las trampas de la fe, México, Fondo de Cultura Económica.

Peñalosa, Joaquín Antonio (1988) «El capitán Juan Camacho Jayna, alcalde mayor de San Luis de Potosí», en Joaquín Antonio Peñalosa, Letras virreinales de San Luis Potosí, San Luis Potosí, Universidad Autónoma de San Luis Potosí, pp. 111-136.

Reyes Gómez, Fermín de los (2001), «Con privilegio: la exclusiva de edición del libro antiguo español», Revista General de Información y Documentación, XI, 2, pp. 163-200.

Reyes Gómez, Fermín de los (2010), «La estructura formal del libro antiguo español», Paratesto, 7, pp. 9-59.

Ruiz, Facundo (2014), «Prólogo», en sor Juana Inés de la Cruz, Nocturna más no funesta. Poesía y cartas, Buenos Aires, Corregidor, pp. 7-89.

Sabat de Rivers, Georgina (1992), «Los problemas de La Segunda Celestina», Nueva Revista de Filología Hispánica, 1, pp. 493-512.

Sabat de Rivers, Georgina (1995), Bibliografía y otras cuestiúnculas sorjuaninas, Salta, Biblioteca de textos universitarios.

Soriano Vallés, Alejandro (2008), La hora más bella de sor Juana, México, Conaculta.

Soriano Vallés, Alejandro (2014), Sor Filotea y sor Juana. Cartas del obispo de Puebla a sor Juana Inés de la Cruz, México, Consejo Editorial de la Administración Pública Estatal.

Tenorio, Martha Lilia (2011), «En torno a Lírica personal de sor Juana», Nueva Revista de Filología Hispanoamericana, LIX, 2, pp. 553-572. 